\title{
Effectiveness of the use of the E-Gamification strategy to develop the educational achievement of the preparatory students in Dammam City and their attitudes towards it
}

\author{
Hatim Ibrahim ${ }^{1}$
}

Received: 18 November 2019 / Accepted: 12 March 2020 / Published online: 8 April 2020

(C) The Author(s) 2020

\begin{abstract}
The goal of the current research to identify the effectiveness of the use of the strategy of electronic defects in the development of the educational techniques of the students of the middle level in Dammam city and the direction towards it, the descriptive and semiexperimental curriculum was used, for their content for research purposes, and has been The total number of members of the sample (170) students, divided into an experimental group and the number of its members (85) students, the number of members of the control group (85) students and the researcher used the test achievement in the subjects of educational techniques, and the measure of direction towards them and the research found the existence of statistically significant differences, between Average student grades of the experimental group, student grades of the control group, in the dimension measurement, of the attainment test, and the existence of statistically significant differences between the average grades of students of the experimental group and the grades of the students of the control group in the dimensional measurement of the trend measure towards the strategy of the defect Electronic for the benefit of the experimental group.
\end{abstract}

Keywords E-Gamification Strategy· Educational Achievement - The Preparatory Students - Dammam City · Attitudes

\section{An introduction}

Playing is an activity - mental - physical - important for the individual - large or small because of his contribution to the formation of his personality in all aspects: cultural -

Hatim Ibrahim

hgmohsmed@iau.edu.sa

1 Department of Educational Technology, College of Education, Imam Abdurrahman Bin Faisal University, P. O. Box 1982, Dammam 31441, Saudi Arabia 
linguistic - skills - emotional - mental - moral, as it meet various needs such as: recreation - education - emptying excess energy, developing his thinking and It helps him adapt in different environments through training in social role-playing and also helps him to control his emotions and control his stress, and has a different importance from one category to another and is individually or collectively organized or automatically (Richard \& Michael 2017, PP. 499), and Educational games provide a fertile environment that helps to grow due to the advantages and excitements that provoke motivation and positive attitudes towards them, and urges active interaction with the educational material, which makes the individual attracted to it and seeks to deal with it in an entertaining and enjoyable way to achieve the objectives of the scientific subject Emotional, cognitive, skilled (Richard \& Michael 2017, PP. 507).

Stephen, \& Martin, (2010, P.105) considers it an educational experience that provides entertainment and fun for learners of all ages and different categories, and serious educational electronic games give excitement and motivation to learning as they address the most The areas of school curricula, providing a kind of education focused on complex skills. Communication is so constant in their daily dealings that they have become their language, communicating through them, expressing themselves while playing electronic games and enthusiastically contributing to online group games (Stephen, \& Martin, 2010, P. 110), Therefore, many educators and education experts believe that there are serious difficulties in integrating this generation of learners into education through traditional education activities, because this is because the formal form of education may fail to meet the needs, inclinations and expectations of these learners, which may lead to their aversion to ways of Traditional teaching compared to their technological activities in their normal lives.

The wide spread of e-learning games has been a natural product of the success of their industry as they have become easy to use and the individual does not need to know them, whether electronic or traditional, in order to be able to play (Salen \& Zimmerman 2004). Mobile phones have become easier to use, resulting in the spread of this type of game, and have also succeeded as a recreational vehicle through which the individual can discover and experience without the risk of responsibility as well as the obsession with failure to accomplish tasks (Simões, \& DíazRedondo., \& et al, 2013, p. 350)., This widespread spread has had psychological and social implications, which has made it the focus of the attention of psychologists and sociologists to determine its pros and cons because the electronic game is not only for entertainment (Werbach \& Hunter 2012). And objectives: cultural - political - religious, because the game affects the player directly to the extent that he applies these games in his life, and that means profiling behavior as the maker of these games wishes (Simões, \& DíazRedondo., \& et al, 2013, p. 345). Positive and negative: Because of its concepts and lessons, it also affects the educational process.

\section{Contribution of this paper to the literature}

1. Trying to reveal the effectiveness of the E-Gamification strategy in the educational achievement of graduate students. 
2. Trying overcoming some of the difficulties faced by graduate students in understanding assimilation.

3. This research may contribute to the attention of those involved in the educational process in the production of curriculum games covering all its subjects.

4. The current research may pave the way for new research on e-mining strategy in other aspects.

Problem of research Electronic games have spread dramatically in the world, electronic games have become modern for leisure time, and even exceeded the free time to occupy the largest time in the life of this generation, so we had to use these games in the educational process to motivate learners to learn, And its impact on the development of achievement among graduate students, because of the possession of these games in providing the opportunity for learners to research, survey and refine their scientific skills, and the problem of research is determined by answering the following main question: Is there effective use of the strategy of electronic games to develop Educational achievement and direction among the students of the preparatory level in Dammam city and the direction towards it?, and the main question branch of the following sub-questions:

1. How effective is the use of the E-Gamification strategy to develop the educational achievement of middle school students in Dammam?

2. What are the trends of preparatory students in Dammam city towards using the eplay strategy?

Research objectives identifying the effectiveness of the use of the strategy of electronic defects in the development of the educational techniques of the students of the middle level in Dammam city and the direction towards it..

\section{Theoretical framework}

Educational games or educational games referred to by Kapp (2012) as activities performed by the student and may make an effort, through certain laws that are explained in advance and related to the subject of the lesson it is a tool aimed at developing the child's own and mental abilities through activities including Various and purposeful types, a situation that is raised when the child can act and interact with things, something that helps him to exercise his intelligence and express his opinion and feel the pleasure of education.

Also summarized (Louise, \& Lise, \& et al, 2010, pp: 252-270 ; Luisde, \& Adrián, \& et al., P., 2014, pp: 82-92 ; Kapp, 2012), the benefits of educational games: provide the learner with experiences closer to the scientific reality than any other educational medium, reveals to the learner some important aspects of life situations that must devote the greatest effort to them or specialize in them in the future, provide safety and security to the learner, increase the motivation of the learner to learn, can Learners learn all kinds of learning: cognitive, psychological and emotional, enabling educators and 
parents to judge the ability of learners to apply the facts, concepts, principles and skills they have studied to different life situations, making the role of the learner positive in the learning process more than any means Similar, the role of both the teacher and the learner differs in the case of the use of educational games, the teacher did not become the only judge on the effectiveness of the student behavior and did not become the source of information but the game itself, suitable for scientific research purposes.

The E-Gamification strategy has also enjoyed many educational characteristics, including: the learner should know his role clearly to participate in the game and know the goal of the game (Mahmoud, \& Awad, 2014, p. 33), the program should have a motivating force to stimulate the enthusiasm of the learner to work longer. To use animation and colors as the basis for the elements of the game, the ultimate goal of the game must be clearing the mind of the learner to work to achieve it clearly and use the information and instructions that explain the path he has to take (McGonigal, \& Reality., 2011, p. 152).

The E-Gamification strategy has also enjoyed many educational characteristics, including: the learner should know his role clearly to participate in the game and know the goal of the game (Mahmoud, \& Awad, 2014, p. 33), the program should have a motivating force to stimulate the enthusiasm of the learner to work longer. To use animation and colors as the basis for the elements of the game, the ultimate goal of the game must be clear in the mind of the learner to work to achieve it clearly and use the information and instructions that explain the path he has to take (McGonigal, \& Reality., 2011, p. 152)., Experimental: The games are experimental by nature, whoever plays these games uses their multiple senses in every action or interaction within the game and there is a reaction which is fast feedback (instant) through which the alternatives are tested and the user learns for those games through results (Christa, \& Andrew \& et al, 2014). Players also analyze receiving information and apply knowledge and skills to formulate strategies and decision-making (Deterding, \& Khaled., \& et al., 2011).

Prepare the strategy The stages of the formation of the strategy of electronic games: the strategy went through six stages, explained as follows: the first stage: determining the time followed to complete the tasks and educational procedures according to the level of each educational game, the second stage: begins with the announcement of the first task which includes the ladder games, With specific objectives and rules for each task related to the game, phase III: allows to practice new games in their nature and in their official quality (graphic) and audio, phase IV: this stage is also the stage of development of the game and the emergence of adventure games and puzzles as well as role games, stage 5: This phase is in line with the use of multimedia technologies developed specifically for this purpose: real-time 3D image processing, parallel calculation, special processors, CD use and games on local networks and online, Stage 6: the stage of control of excellence and seriousness in the implementation of tasks and students who get the high badges in the grades obtained in the performance of educational tasks followed according to each stage of the game that aims to develop the skills of educational achievement, stage 7: one of its characteristics is the appearance of the best students In achieving the learning outcomes that the course aims to and content education in educational communication techniques. 
The strategy also relied on the foundations in the selection of electronic games, including: 1. Clarity of objectives: where the goal of the game is clear, as the desired results of this game should be clear to both the teacher and the learner, and therefore it must be made sure that the objectives of the game chosen are clear so that Learners can know exactly what they are required to do, 2. Game instructions and rules: Games allow the player to acquire a range of knowledge and information through his practice, where the game was chosen with abundant information, clear rules, 3. Educational content: The educational content of the game explains those topics that are taught, even if the content of the game is not closely related to the curriculum, the game must have a clear and simple representation of some of the concepts that are taught,4. Feedback: Feedback for players has been fun and attractive, and verbal directions or hints can help keep the player focused during the game, 5. Opportunities for teamwork, cooperation and creativity: the use of games that encourage collaborative work between players, and the use of games that encourage creativity, so it was necessary to check whether the materials included in the game encourage students to be creative by enabling them to make decisions and participate in Ideas, 6. Evaluation and follow-up: To clarify the course of the learner's progress within the game, so that the teacher can analyze the molecules that are difficult to understand by the learner and that need more work, and in fact not all software is available this feature, 7. Assistance: The game provides help to the learner includes clarifying all the tasks to be performed, and in case possible this help was printed and made available to students, in which case attached with the game a guide explaining to the teacher how to use this game, 8. Game type: There are many types of games that are used in accordance with educational topics and tasks required: puzzle games, fantasy, adventure, simulation, some games require certain technological skills as well as certain strategies, 9. The nature of participation: to assess whether the role of the player is negative or positive, then the computer detects and reinforces the consequences of the decisions made by the player in the case of the right decisions and negatively in the case of wrong decisions 10. Difficulty level: Some games allow choosing the level of difficulty, others have adjusted their difficulty level based on the evolution of the player's performance in the game levels, and this first style gradually makes the game more fun, as it becomes more challenging, 11. Technical bases: 11-1. User interface: The user interface of the game is clear, intuitive, easy to use and suitable for the age group used for this game, 11-2. Save and download the game: It is best that the game enables the learner to save the current level that has been reached and resume play at a later stage or another time, especially if using large games that require a long time to play, 11-3. Sound: If the game has sounds, it's helpful to have a mute button, 11-4. Customization: If large games are used, it must be verified that the game can provide the player with the freedom to choose the character, color, scenario or level of difficulty; Educated in particular.

\section{A scenario for using a game strategy in the class}

It was the responsibility of the researcher to try this game and make sure of the appropriate content for the characteristics of learners, as well as for the content of the lesson and to understand the rules of the game, and determines the previous experiences necessary for the practice of the game, as all the possibilities of the game were exploited in order to 
achieve the objectives of its use in the educational process, as was helped Learners understand and study the problems that are expected to occur when they are actually used in the lesson, and know how willing their students are to learn and know their level of computer skill and based on their skill assessment, the teacher decides not to use the game.

During the lesson, the researcher at the beginning of the presentation explains the lesson's objectives to learners, shows the game to learners and explains how to perform basic tasks (such as access to help, sailing through menus, or changing any character), and then begins working through the game and in the meantime must Teacher to encourage students to good, safe and healthy play habits, like any other activity should use electronic games wisely and appropriately, so as not to negatively affect the health of learners, so the teacher, parents and learners must have knowledge of the good habits of the games must Ensure that the use of these toys does not adversely affect children's mental and physical health.

Also organized the time spent by learners during the game, they may encounter some problems because some learners cannot stop playing because of their immersion in play and boredom in case of leaving the game, it is important that the teacher communicate with his pupils while giving them part of his time to hear them and know How to achieve success when they play.

\section{Research tool}

1. Achievement test: In the light of general objectives and behavior, scientific content of computer and information technology, a learning test of the type of objective questions was prepared, including the test (33) questions divided into two parts, the first part is correct or wrong questions and their number (15) A question, the second part is a choice of multiple and numbered (18) questions. Test question levels were determined to measure cognitive field levels by Bloom's classification, and included knowledge, understanding, application, analysis, composition, and evaluation, a test specification table was prepared: based on the relative weight of each of the target module sub-subjects. The test was presented to a group of experienced arbitrators to measure the validity of the test, and to calculate the test stability factor by means of half-fragmentation using the 'Spearman, Brown' equation of 0.93 (Brown, \& Armstrong, \& et al, 1998).

2. Measure trends towards the use of electronic Gamification strategy and the scale may be of five dimensions: self-efficacy, test anxiety, internal orientation of the goal, external orientation of the goal, efficiency, the final picture of the scale has included (50) words, most of the phrases have been formulated in the form of Estimates in the positive direction (25) are positive, and the scale includes some negative-trended terms (25) negative.

3. Methods used in the research: The research required the use of the following statistical methods to process the data related to it: $3-1$. Calculating the averages and deviations of the standard deviations of the grades of students of the experimental and control groups in the achievement test and the measure of trends through the strategy of defects Electronic, 3-2. The use of the Alpha Cornbrash coefficient calculation and the use of half-fragmentation using the 'Spearman Brown' equation to calculate stability coefficients. To make sure the two groups are equal (Tables 1 and 2). 
The results indicate that there are no statistically significant differences between the grades of students in the experimental and control groups, indicating the equivalence of the two groups and the possibility of being selected as research groups.

- The educational content was taught in accordance with the strategy of the trial group, and in the traditional way of the control group, the trial lasted for 8 educational sessions at 8 weeks, preceded by a week of tribal application and followed by the week of the application dimension.

- Apply the collection test and the motivation altogether to learn English on the results of the two research groups and collect the results.

- Analyze and statistically process data and results using SPSS.

- Make recommendations and research proposed in light of the findings.

Results and explanations of the research to test the validity of the first hypothesis which states 'there are statistically $d$ differences between the average grades of students of the experimental group and the grades of the students of the control group in the after-measurement of the achievement test in favor of the experimental group, the average student grades were calculated in the experimental group The control group in the collection test, the standard deviation, the value of ' $\mathrm{T}$ ' and the results are illustrated by a Table 3 .

The results of the (Table 3 ) indicate that the average score of students of the experimental group 27.7 and the value of a standard deviation of 3.9 and the average score of the students of the control group, 17.9 and the standard deviation, 3.8 and value (T) was 8.14 , i.e. it is a statistical function at the level of the indication of 0.01 and the results shown in the table indicate acceptance of the imposition The first experiment.

To test the validity of the second hypothesis, which states that 'there is a statistical lyceum between the average grades of the experimental group students and the grades of the students of the control group in the dimensional measurement of the trend measure towards the use of the E-Gamification strategy for the experimental group', the average student grades were calculated. For each of the experimental group officer in the measure of motivation towards learning English, a Table 4 illustrates the calculation of the value of ' $\mathrm{T}$ ' and the results.

The results of Table 4 indicate that the average grades of students of the experimental group 163.2 and the value of a standard deviation of 2.5 and the average score of the students of the control group 135 and the standard deviation 2.4 and that the value of ' $\mathrm{T}$ ' reached 9.2 i.e. it is a statistical function at the level of 0.01 and the results shown in the table indicate the acceptance of experimental imposition Second, this can be

Table 1 Results of applying the pre-collection test to the control group and the experimental group. Computational deviation standard value ' $\mathrm{T}$ '

\begin{tabular}{lllll}
\hline Group & Sample & Average & DF & Value 'T' \\
\hline Control group & 85 & 16.63 & 2.59 & 0.94 \\
Experimental group & 85 & 16.59 & 2.54 & \\
\hline
\end{tabular}


Table 2 Results of applying the tribal trend oscale to the control group and the experimental group

\begin{tabular}{lllll}
\hline Group & Sample & Average & DF & Value ' $\mathrm{T}$ \\
\hline Control group & 85 & 131 & 2.4 & 0.29 \\
Experimental group & 85 & 132 & 2.6 & \\
\hline
\end{tabular}

explained by the fact that students who learned using the game strategy were more positive than students who were educated using traditional teaching methods, and student trends were adjusted as a result of using the game strategy.

\section{Discuss results}

1- With regard to the educational aspect: The strategy of electronic games prepared has helped to form a positive role through a real-life context in providing students with many knowledge and skills, many electronic games in which students need to acquire new and multiple skills and communication or Sharing with other players inside or outside the game, players analyze the receiving information and apply the prior knowledge and skills to formulate strategies and decision-making and then study the results, and thus helped the strategy of electronic games to advance the level of educational achievement in two ways Knowledge and knowledge of the learning topics addressed in the current research; Where the aspiration of the learning environments of the learner can experiment and get feedback on his suggestions and strategies, this is a new knowledge method for learners in seeking knowledge and acquiring skills in a constructive way, and knowing what information or techniques to apply in Certain situations often lead to more success, especially solving problems that often involve many interactions during the game, and this is consistent with the findings of a study (Çeker, \& Özdaml1, 2017 ; Burke., 2014 ; Christa, \& Andrew \& et al, 2014 ; Deterding, \& Khaled., \& et al., 2011 ; Gressick, \& Langston., 2017 ; Hamari, \& Koivisto, 2014).

2- On the direction side: The e-gaming strategy helped to: develop the problemsolving skills of students due to the obstacles they encounter during play, made the student more committed to the rules and instructions organized, increasing the ability of the student to perform a number of tasks simultaneously for what they provide From the ability to synchronize eye movement with the hand, some mental skills and abilities have grown, achieved the ability to plan, analyze, manage resources and speed of intuition, helped to overcome the factor of time and space and reduce risk and responsibility, contributed to the education of complex and

Table 3 Results of the application of the post-collection test to the trial group and the control group

\begin{tabular}{lllll}
\hline Group & Sample & Average & DF & Value 'T' \\
\hline Control group & 85 & 17.9 & 3.8 & 8.14 \\
Experimental group & 85 & 27.7 & 3.9 & \\
\hline
\end{tabular}


Table 4 Results of applying the trend oscale to the experimental and control group

\begin{tabular}{lllll}
\hline Group & Sample & Average & DF & Value 'T' \\
\hline Control group & 85 & 135 & 2.4 & 9.2 \\
Experimental group & 85 & 163.2 & 2.5 & \\
\hline
\end{tabular}

complex things, helped to raise the level of Through an educational discussion, students' awareness deepened the increased desire to compete and challenge among students.

3- This finding is consistent as important as the strategy of defects in raising the level of achievement in the mental activity carried out by students, which shows the impact of academic excellence, the achievement works to achieve progress and eliminate the deposits of underdevelopment from it, works to know the extent of the benefit sought by the learner and know his level, is important in The life of the individual because of the decisive educational decisions that result from its results, \& who recommended the impact of the games in enhancing motivation among learners, and its importance in the educational process because of its positive effects in improving students' effective participation in learning activities. With more positive effects on collection.

\section{Recommendations}

1. Expand the use of e-play strategy in teaching rather than the usual methods of teaching.

2. Benefit from the difficulty in teaching graduate courses.

3. Holding training courses to learn about the strategy of electronic games and ways to use them in education as well as its preparation and design

4. Work on the development of the curriculum in line with modern technologies in education, including (games, electronic games).

\section{Proposed research}

In light of the objectives of the current research, and based on the findings of the study in the subject of research, it is suggested that the following studies and researches can be carried out:

5. The impact of the use of the strategy of playing on the development of creative thinking skills in students of education technology.

6. The impact of cloud-based applications on the development of survey and visual thinking skills in middle school students.

7. The effectiveness of the strategy of playing in a participatory educational environment on the development of creative thinking among middle school students. 
8. The impact of the use of Moocs learning platform slurs strategy in the development of academic achievement and visual thinking among students of education technology.

\section{Compliance with ethical standards}

Conflict of interest no conflict is present.

Open Access This article is licensed under a Creative Commons Attribution 4.0 International License, which permits use, sharing, adaptation, distribution and reproduction in any medium or format, as long as you give appropriate credit to the original author(s) and the source, provide a link to the Creative Commons licence, and indicate if changes were made. The images or other third party material in this article are included in the article's Creative Commons licence, unless indicated otherwise in a credit line to the material. If material is not included in the article's Creative Commons licence and your intended use is not permitted by statutory regulation or exceeds the permitted use, you will need to obtain permission directly from the copyright holder. To view a copy of this licence, visit http://creativecommons.org/licenses/by/4.0/.

\section{References}

Brown, S., Armstrong, S., \& Thompson, G. (1998) Motivating students. London, Kegan Page Published In Association with the Staff and Educational Development Association.

Burke, B. (2014). Gartner Redefines Gamification. Retrieved from http://blogs.gartner.com/brian_burke/2014 /04/04/gartner-redefines-gamification/.

Çeker, Eser \& Özdaml, Fezile (2017): What "Gamification" is and what it's not, European Journal of Contemporary Education, 2017, 6(2) https://doi.org/10.1016/j.chb.2012.06.007.

Christa, R Nevin, \& Andrew, O \& Westfall, J \& Martin, Rodriguez, \& Donald, M \& Dempsey, Andrea \& Cherrington, \& Brita, Roy \& Mukesh, Patel,\& James, H \& Willig (2014): Gamification as a tool for enhancing graduate medical education. Nevin CR, et al. Postgrad Med J; 90:685-693. https://doi. org/10.1136/postgradmedj-2013-132486

Deterding, S., \& Khaled, R., \& Nacke, L., \& Dixon, D. (2011): Gamification: Toward a Definition, Proceedings of the CHI 2011, Vancouver.

Gressick, J. \& Langston, B. (2017): The Guilded Classroom: Using Gamification to Engage and Motivate Undergraduates, Journal of the Scholarship of Teaching and Learning, Vol. 17, No. 3, July, pp. 109-123. https://doi.org/10.14434/josotl.v17i3.22119.

Hamari, Juho \& Koivisto, Jonna (2014): Measuring flow in Gamification: Dispositional Flow Scale-2. Computers in Human Behavior 40, 133-143.

Kapp, K. M. (2012): The Gamification of Learning and Instruction: Game-based Methods and Strategies for Training and Education, Pfeiffer, San Francisco.

Louise, Sauvé, \& Lise, Renaud, \& David, Kaufman, (2010). The Efficacy of Games and Simulations for Learning, 252-270.

Luisde, M. \& Adrián, D. \& Joseba, S. \& Carmen, P. (2014). An empirical study comparing gamification and social networking on e learning. Computers \& Education. Volume 75, June 2014, Pages 82-91. https://doi. org/10.1016/j.compedu.2014.01.012.

Mahmoud, Ahmed Awad Amin (2014): Using Games to Promore Student 'Motivation towards Learning English, Al-Quds Open University Journal for Educational and Psychological Research and Studies, vol. 2, p5, AlQuds Open University, pp. 11-33.

McGonigal, J, \& Reality, B. (2011): Why Games Make Us Better and How They Can Change the World, Penguin Group, New York.

Richard, N. \& Michael, B. (2017).Enhancing instructional outcomes with gamification: An empirical test of the Technology Enhanced Training Effectiveness Model. Computers in Human Behavior. Volume 71, June 2017, Pages 499- 507. https://doi.org/10.1016/j.chb.2015.07.031.

Salen, K. \& Zimmerman, E. (2004) Rules of play: Game design fundamentals. MIT Press, Cambridge. 
Simões, Jorge \& DíazRedondo, Rebeca \& Ana, Fernández, Vilas. (2013).A social gamification framework for a K-6 learning platform. Computers in Human Behavior. Volume 29, Issue 2, March 2013, Pages 345353.

Stephen, Tang \& Martin, Hanneghan (2010): Designing Educational Games: A Pedagogical Approach, 108125 http://www.igi-global.com/gateway/.

Werbach, K., \& Hunter, D. (2012): For the Win: How Game Thinking Can Revolutionize Your Business, Wharton Digital Press, Philadelphia.

Publisher's note Springer Nature remains neutral with regard to jurisdictional claims in published maps and institutional affiliations. 